\title{
CONSIDERAÇÕES SOBRE AS ESCALAS ESPACIAIS DE ANÁLISE DA INDÚSTRIA NO BRASIL
}

Olga Lúcia Castreghini de Freitas Firkowski Professora da Universidade Federal do Paraná

Pesquisadora do CNPq

olgafirk@ufpr.br

\section{Resumo}

Com o presente texto objetiva-se tecer considerações sobre as discussões relativas às escalas espaciais de análise em Geografia Industrial no Brasil, destacando-se o processo de desconcentração e as diferentes expressões espaciais do mesmo, tomando-se como referência os anos de 1980 e a atualidade. Naquele período o processo restringia-se ao entorno de São Paulo, sobretudo a um raio de $150 \mathrm{~km}$ a partir da capital. $\mathrm{Na}$ atualidade os debates são incentivados pela recente localização da indústria em lugares distantes daqueles tradicionais, alterando as explicações anteriores. Nesse contexto, os conceitos de brownfield e greenfield são apresentados como possibilidades de compreensão das duas faces do processo de desconcentração da indústria brasileira.

Palavras-chave: Indústria, desconcentração, escala de análise, Geografia Industrial, espaço.

\begin{abstract}
This work presents some considerations on the spatial dimension analysis related to Brazilian Industrial Geography. This presentation takes in account the desconcentration process and the different spatial expressions referencing 1980's and present days. In that time the desconcentration process was restricted to $150 \mathrm{~km}$ neighbourhood around São Paulo City. In present days the debate is centered on discussions on other industry location different than the traditional and propitiating new explanations for this facts. In this context brownfield and greenfield concepts are presented as a way for explaying the face of the brazilian industry desconcentration.
\end{abstract}

Key Words: industry, desconcentration, analysis scale, industrial geography, space.

\section{$0 \bigcirc 0$}

O presente texto tem como objetivo tecer considerações sobre as discussões relativas as escalas espaciais de análise da indústria no Brasil. Para tanto, serão revisitadas algumas formulações teóricas utilizadas por aqueles que trabalham com a Geografia Industrial, e identificadas a emergência de outras que certamente contribuirão para o avanço da produção nessa área do conhecimento.

Para Fischer (1994), há duas perspectivas principais que caracterizam a análise industrial realizada no âmbito da Geografia, são elas: a setorial e a espacial. Enquanto a setorial dedica-se à investigação dos ramos de atividade industrial, a espacial dedica-se a compreensão da relação entre a indústria e o espaço geográfico.

É no âmbito da segunda perspectiva que serão tecidas algumas considerações sobre as discussões, recentes ou não, que parecem ter influência decisiva nas pesquisas de Geografia Industrial no Brasil. Assim, concomitante a emergência de novos termos de origem inglesa, e sua incorporação ao vocabulário acadêmico, persistem algumas posições teóricas não tão pertinentes para a explicação do processo de localização industrial no território brasileiro.

Para alcançar os objetivos propostos, o texto será dividido em três partes principais, além da introdução e das considerações finais. Na primeira são apontadas evidências acerca do processo de desconcentração da indústria no Brasil. Na segunda parte, resgata-se o marco teórico das discussões relativas a descon- 
centração da indústria brasileira, tendo São Paulo como foco central das análises, bem como chama-se a atenção para importantes mudanças nas escalas espaciais de análise desse processo, a partir do movimento recente de implantação de indústrias em outros lugares, para além de São Paulo (metrópole e interior). $\mathrm{Na}$ terceira e última parte, são apresentadas algumas reflexões sobre a capacidade operativa dos conceitos de brownfield e greenfield no âmbito das análises sobre a desconcentração da indústria brasileira.

Portanto, esse texto, apesar de não ser conclusivo ou definitivo, pretende chamar a atenção para algumas questões recorrentes nos trabalhos de Geografia Industrial no Brasil, apontando para a necessidade de resgatar possibilidades interpretativas já formuladas no interior da Geografia ou, ainda, construir novas possibilidades em face das transformações na realidade.

\title{
Algumas evidências da desconcentração da indústria
}

Embora o debate sobre a desconcentração da indústria no Brasil ocorra em meio a uma grande diversidade de posições sobre a questão e se relacione a totalidade da atividade industrial, parte do argumento ora apresentado será respaldado na análise do deslocamento da indústria automobilística pelo território nacional ${ }^{1}$.

No contexto dos investimentos ocorridos após os anos de 1990, a indústria automobilística pode ser tomada como um exemplo bastante elucidativo das transformações em curso no Brasil, quando se verifica uma incessante busca por novas localizações no interior desse segmento industrial, isto porque, como afirma Harvey (1992, p. 307), a trajetória do desenvolvimento capitalista "não é previsível em nenhum sentido comum exatamente porque sempre se baseou na especulação - em novos produtos, novas tecnologias, novos espaços e localizações, novos processos de trabalho" sempre na perspectiva da obtenção de maiores lucros. No Brasil e particularizando para a indústria automobilística, isso redundou na dispersão das novas plantas por diferentes estados, muitos dos quais sem nenhuma tradição nesse setor industrial, tal foi o caso do estado do Paraná.

A análise dos novos investimentos por estado no período 1996-1999, indica, segundo Rodrigues (2000, p. 127), que

\begin{abstract}
simultaneamente ao movimento de concentração de novos investimentos no eixo Rio de Janeiro - São Paulo, ocorreu uma desconcentração da produção física em direção aos estados vizinhos a São Paulo e a outros que souberam aproveitar a mudança do padrão de desenvolvimento brasileiro logo após a abertura comercial ao exterior e o início do período de estabilização de preços... [tais fatores] explicam o aumento dos anúncios de investimentos em 1997, particularmente em sete estados: São Paulo, Rio de Janeiro, Rio Grande do Sul, Paraná, Bahia, Ceará e Amazonas.
\end{abstract}

$\mathrm{Na}$ tentativa de compreender a dimensão regional dos investimentos industriais recentes, Pacheco (1999) conclui que estão em curso importantes alterações no padrão de localização da atividade produtiva no país, onde a desconcentração da indústria automobilística tem se destacado. Isto porque, para o Autor, o processo de desconcentração não pode tomado de modo uniforme para o conjunto da atividade industrial, mas sim para setores específicos.

Nessa perspectiva e após analisar dados relativos ao Valor da Transformação Industrial (VTI), à distribuição do emprego industrial (RAIS e CAGED) e as intenções de localização de novos investimentos obtidas através do Ministério do Desenvolvimento, Indústria e Comércio Exterior, o Autor distinguiu grupos de gêneros de atividade industrial e seus respectivos graus de participação no processo de desconcentração. Assim, os gêneros que tiveram uma ampla desconcentração no período compreendido entre meados da década de 1980 e meados da década de 1990 (até 1997) foram: calçados, têxtil, produtos 
alimentares e bebidas; os que tiveram baixa desconcentração, até porque já haviam se desconcentrado no período anterior 1970-1985, foram: química, papel e celulose e extração de minerais; os que tiveram desconcentração restrita aos estados do sul e sudeste foram: material de transportes, mecânica, minerais não metálicos, metalúrgica e material elétrico e de comunicações. Observando a distribuição desses últimos, o Autor conclui pela ocorrência de uma desconcentração concentrada, na medida em que predomina a localização nos estados do sul e sudeste do país. Concomitante a essa desconcentração ocorreria também uma forte concentração dos setores ligados as telecomunicações e informática em São Paulo.

Concentração e desconcentração devem ser compreendidos como duas faces de um mesmo processo, portanto, a partir de uma relação dialética, onde, ao mesmo tempo em que as atividades produtivas (as plantas industriais propriamente ditas) se desconcentram territorialmente, inserindo novos lugares ao processo produtivo, têm-se, por outro lado, uma grande concentração, em poucos lugares privilegiados, das atividades relacionadas à decisão e gestão, além da produção de inovação e informação.

Dessa forma, alguns tipos de atividades possuem maior liberdade de localização, enquanto outras seguem se concentrando cada vez mais. Não surpreende, portanto, o fato de São Paulo seguir liderando quanto ao montante de investimentos, na medida em que parte considerável dos mesmos tem como destino outros setores econômicos que não o industrial, particularmente as telecomunicações e informática, como destacado anteriormente.

Negri (1996), ao analisar as mudanças no padrão de distribuição da indústria paulista, enfatiza o processo de desconcentração industrial a partir da metrópole. Para ele o processo de interiorização da indústria paulista deve ser compreendido como um movimento (processo) que transcende os aspectos relacionados simplesmente às decisões locacionais ou às vantagens do interior, quando comparadas à metrópole.

Para o Autor a desconcentração industrial pode ser mensurada a partir das "alterações na distribuição espacial absoluta ou relativa de variáveis como número de estabelecimentos, pessoal ocupado, valor da produção e valor da transformação industrial" - VTI, e se expressa em dois níveis, "a) do estado de São Paulo em direção ao resto do país, que implicou reduzir de $58,2 \%$ para $49,2 \%$ sua participação no VTI do Brasil, entre 1970 e 1990 e b) da Região Metropolitana em direção ao interior paulista, que implicou reduzir de 74,7\% para 53,3\% sua participação no VTI estadual, no mesmo período" (NEGRI, 1996, p. 13), ou ainda de $43,4 \%$ para $26,2 \%$ se considerado o VTI brasileiro. Nesse mesmo período o interior paulista tornou-se o segundo aglomerado industrial do país concentrando, em 1990, o equivalente a $23 \%$ do VTI brasileiro.

A inserção de parte da chamada "periferia" nacional no processo de desconcentração ${ }^{2}$ estaria ocorrendo paulatinamente desde os anos de 1980, inicialmente como resultado da política pretendida com o I e II Planos Nacionais de Desenvolvimento (PND), através da qual reforçou-se certos gêneros industriais fortemente relacionados à exploração intensiva de recursos naturais e, portanto, cuja localização acompanhava a ocorrência dos mesmos, distribuindo-se pelo interior do país, ou ainda relacionados à distribuição estratégica dos Pólos Petroquímicos, em diferentes pontos do país.

\section{As escalas espaciais de análise}

Tendo em vista a compreensão das escalas espaciais de análise da desconcentração da indústria brasileira, com as ressalvas já efetuadas, parece oportuno salientar as modificações ocorridas no processo tal qual ele se apresentava até o final da década de 1980 e início de 1990, quando comparado ao final da década de 1990 e início dos anos de 2000. No primeiro momento, quando o grande destaque do processo 
era o interior do estado de São Paulo, além da própria metrópole, quando o deslocamento de unidades industriais se dava predominantemente para o espaço compreendido num raio de cerca de $150 \mathrm{~km}$ a partir da cidade de São Paulo [Azzoni (1985), Lencioni (1991), Sampaio (1987), dentre outros], portanto, um “interior próximo" e não distante à capital, na perspectiva de dispor das condições gerais de produção, como que numa ampliação das condições existentes na capital.

No segundo momento, a partir de meados da década de 1990, uma importante alteração de tendência se observa, isso não quer dizer, contudo, que São Paulo (metrópole) e o interior (do estado) perdem importância absoluta no conjunto, mas que novos locais emergem como atraentes para o grande capital transnacional. O que permite pensar numa ampliação da base de desconcentração e da própria discussão teórica sobre a questão - antes limitada ao caso paulista -, emergindo uma nova escala de análise.

Assim, a realidade apresenta-se diferenciada e faz-se mister diferenciar também os elementos que possibilitam sua compreensão, desvendando novos arranjos capazes de provocar a emergência de novos locais aptos à produção, status que esses mesmos lugares não possuíam num passado recente.

\section{Reversão da polarização, espraiamento da indústria, campo aglomerativo: a escala tradicional de análise.}

No interior das distintas interpretações sobre a problemática da desconcentração da indústria brasileira, com ênfase na análise de São Paulo, um importante conceito se destacou, qual seja o de polarization reversal ou reversão da polarização. Tal conceito foi muito debatido por geógrafos e economistas particularmente nos anos de 1980 e com importantes desdobramentos analíticos nos anos de 1990.

O conceito de reversão da polarização originou-se nos trabalhos desenvolvidos nos Estados Unidos e Europa, quando Richardson (1977) afirmava existir um ponto de reversão do modelo espacial de crescimento e desenvolvimento do país, nesse momento a concentração existente cessaria e daria lugar à desconcentração urbana. Assim, o Autor destacava a participação de um centro metropolitano cujo crescimento se desaceleraria em relação às demais cidades do país, as quais ganhariam importância.

Como tal conceito baseou-se na realidade vigente nos países centrais, alguns autores puseram-se a debater sobre sua aplicação à realidade dos países periféricos. Nesse contexto o Brasil se destacou como um vasto campo de discussões ora contra, ora a favor da ocorrência do processo.

No âmbito da Geografia, tais discussões fomentaram um acirrado debate entre Townroe e Keen (1984) e Townroe e Hamer (1984) de um lado e Storper (1984) de outro, protagonizado na Revista Regional Studies. Ao longo do ano de 1984, foram inúmeros artigos, que desencadearam réplicas e tréplicas, sobre a particularização da temática para o estado de São Paulo.

No Brasil, vários autores passaram a considerar o conceito de reversão da polarização no conjunto de sua argumentação a respeito da desconcentração industrial paulista, porém, uma das mais significativas contribuições contrárias a ocorrência de tal processo foi a do economista Azzoni (1985), que discutiu o caso paulista em face do suposto processo de reversão de polarização no Brasil.

O que para Townroe e Keen (1984), após estudos sobre o estado de São Paulo, configurava-se como reversão da polarização, na medida em que os Autores apontavam o alto crescimento relativo de certas cidades do interior do estado como maior do que o de São Paulo (capital), revelando, assim, uma desconcentração urbana e da atividade econômica; para Storper (1987) tratava-se simplesmente de uma relocalização de unidades produtivas de modo a se estender as vantagens da localização metropolitana para o seu entorno.

Azzoni (1985, p. 19), citando Richardson (1977) apontava as cinco fases que caracterizariam o pro- 
cesso de reversão da polarização, sendo elas: 1) um processo inicial concentrador; 2) um estágio mais avançado onde outros centros apresentariam maior crescimento que a cidade central (metrópole); 3) início da reversão propriamente dita, a partir da dispersão para outras regiões; 4) expansão do processo para centros regionais, extrapolando a área central, foco inicial do processo e, finalmente, 5) quando a área central e os centros regionais perdem população absoluta.

Azzoni (1985) e Storper (1987) consideravam que o processo de reversão da polarização não podia ser medido exclusivamente através de dados relativos à desconcentração urbana, como na origem das teorizações sobre o processo, mas incluíam na análise, além da dispersão da população, a dispersão da atividade industrial. Azzoni (1985, p. 43) chamava a atenção para o fato de que "a existência de uma metrópole nacional congestionada e com altos custos para os empresários não garante uma desconcentração industrial ao nível de áreas distantes do território. Ao contrário, apontam para um preenchimento da área vizinha, inicialmente, com posterior espraiamento para áreas próximas".

Para o Autor, essa "área vizinha" da metrópole era definida como aquela compreendida num raio de cerca de $150 \mathrm{~km}$ a partir da capital paulista, usufruindo das vantagens dessa proximidade espacial e formando um "campo aglomerativo", onde a localização industrial não se limitava à metrópole, mas abrangia o conjunto regional, cuja atração supera a do centro urbano principal (metrópole). Portanto, para o Autor, tratava-se da superação da economia de urbanização como importante condicionante de localização, e da emergência da economia de regionalização como seu sucedâneo.

Dessa forma, Azzoni (1985, p. 22) concluía pela não ocorrência do processo de reversão da polarização, mas pelo processo de espraiamento da indústria dentro da área mais industrializada do país, ao que o Autor denominou "desconcentração concentrada", dado o crescente vínculo gerencial de toda a região com a cidade central (São Paulo) que não perdeu seu poder de comando do processo, mas apenas separou a atividade produtiva propriamente dita daquela de comando e decisão. Essa também foi a conclusão de Lencioni (1991) ao analisar a indústria têxtil em São Paulo.

Assim, "longe de prenunciar uma independência do crescimento industrial com relação à atração exercida pela área central, a dinâmica industrial do anel externo à Área Metropolitana paulista guarda estreita relação com a Capital, caracterizando uma fuga dos custos locacionais maiores do centro" (Azzoni, 1986, p. 66).

\section{Aglomeração poligonal, região concentrada: ampliação na escala de análise}

O processo de desconcentração da indústria brasileira em andamento após meados da década de 1990, dá sinais de ampliação da escala de análise até então restrita ao estado de São Paulo de modo geral e em particular ao entorno metropolitano, na medida em que, novos elementos e novas localizações parecem contribuir para revigorar os debates.

As novas escolhas de localização da indústria automobilística auxiliam a compreensão do novo processo, pois apontam para a incorporação de outros espaços, aumentando crescentemente o raio preferencial de localização industrial, antes restrito a cerca de $150 \mathrm{~km}$ a partir de São Paulo, conforme visto anteriormente (Figura 1).

Como, portanto, explicar essa nova tendência de localização? Como compreender a inserção de novos lugares ao circuito produtivo, tais como porções do Paraná, Minas Gerais e Rio Grande do Sul? 


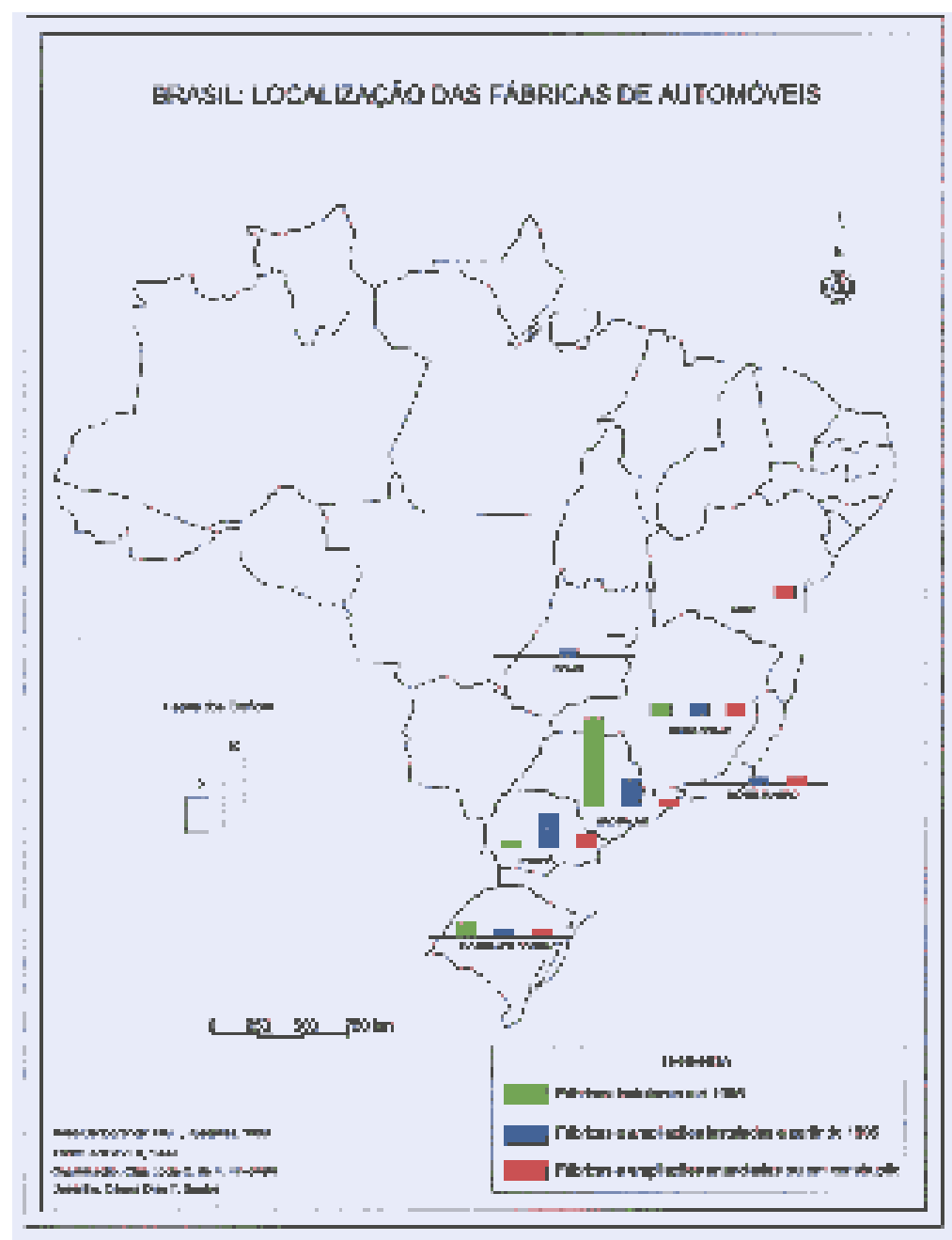

Figura 1: Brasil - Localização das Fábricas de Automóveis

Para Diniz (1993, p. 35) tal processo se explicaria a partir da definição de uma "aglomeração poligonal", onde "um limitado número de novos pólos de crescimento ou regiões têm capturado a maior parte das novas atividades econômicas".

A ocorrência do desenvolvimento poligonal deve-se a ação de cinco forças, apontadas pelo Autor como sendo:

1) surgimento tanto de deseconomias de aglomeração na Região Metropolitana de São Paulo, quanto de economias de aglomeração em outros centros urbanos;

2) ação do Estado, tanto como investidor direto na indústria, quanto promovendo infra-estrutura e concedendo incentivos; 
3) localização industrial próxima às fontes de recursos naturais, particularmente como decorrência da industrialização incentivada na década de 1980 (relacionada ao II PND);

4) forte concentração da renda, das pesquisas e do poder de compra;

5) unificação do mercado nacional.

Para o Autor dois momentos da desconcentração devem ser destacados, no primeiro o grande beneficiado teria sido o entorno de São Paulo e, no segundo, em andamento, seria o polígono formado por Belo Horizonte, Uberlândia, Londrina, Maringá, Porto Alegre, Florianópolis, São José dos Campos e Belo Horizonte, como pode ser observado na Figura 2.

A região beneficiada pelo processo de desconcentração seria caracterizada pela existência de cidades com considerável concentração de serviços, além de infra-estrutura, renda, atividades de pesquisa e ensino e significativa base industrial.

Assim, parece oportuno pensar que o processo de desconcentração da indústria no Brasil inaugura uma nova fase, onde a base territorial passível de receber os novos investimentos industriais se amplia consideravelmente, extrapolando os limites alcançados pelo processo no período anterior, qual seja, São Paulo, metrópole e interior ${ }^{4}$.

Na perspectiva do polígono, tem-se uma grande região no interior da qual é possível a localização industrial em virtude do predomínio de uma certa similaridade em termos das condições capazes de atrair indústrias, tais como tamanho urbano, serviços, infra-estrutura, alcance do mercado consumidor, dentre outras.

Santos (1993) chegava a conclusão semelhante a respeito da existência de um espaço privilegiado, principalmente do ponto de vista da atividade industrial, propondo, num primeiro momento, o conceito de região concentrada e, posteriormente, o de meio técnico-científico. A região concentrada abrangeria os estados de São Paulo, Rio de Janeiro, Paraná, Santa Catarina, Rio Grande do Sul, e parcelas de Mato Grosso do Sul, Goiás e Espírito Santo (Figura 03).

\section{Para o Autor,}

trata-se de uma área contínua onde uma divisão do trabalho mais intensa que no resto do País garante a presença conjunta das variáveis mais modernas - uma modernização generalizada - ao passo que no resto do País a modernização é seletiva.... A região concentrada coincide com a área contínua de manifestação do meio técnico-científico, cuja lógica corresponde às necessidades do presente estágio de desenvolvimento do País ... o meio técnico-científico é o terreno de eleição para a manifestação do capitalismo maduro, e este também dispõe de força para criá-lo. (SANTOS, 1993, p. 39-40)

Assim, tem-se uma nova lógica dada pela divisão territorial do trabalho que se altera no Brasil entre as décadas de 1980 e 1990 e que explica a articulação de cada subespaço ao todo nacional.

É nesse contexto que deve ser compreendida a inserção de novos lugares à dinâmica industrial nacional, dentre eles o Paraná, não apenas porque o Estado é um dos componentes do polígono ou da região concentrada mas, sobretudo, pelo desempenho positivo que tem tido em relação à atração de novos investimentos industriais, notadamente do setor automobilístico. 


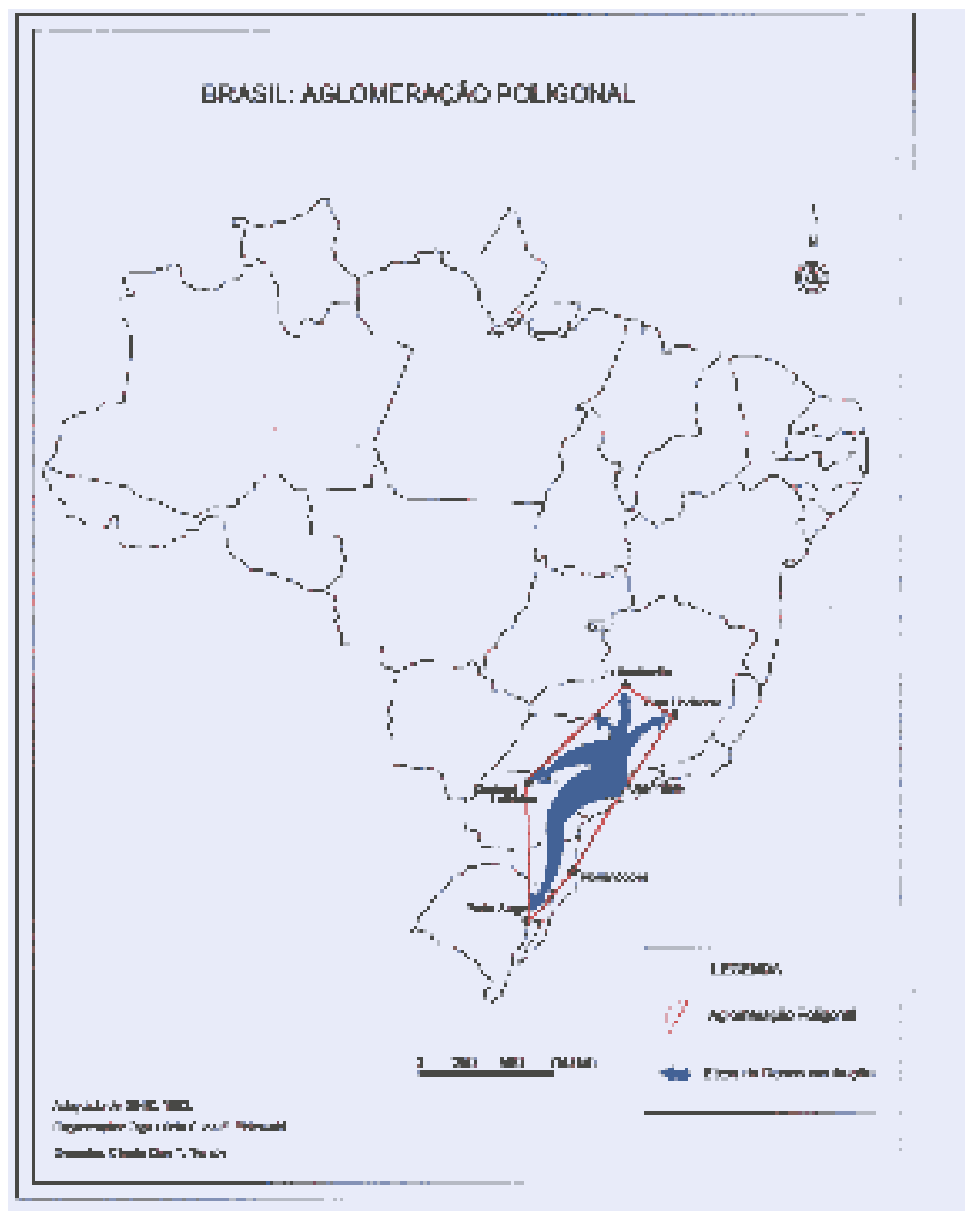

Figura 2: Brasil - Aglomeração Poligonal

Por outro lado, a despeito da existência de várias condições favoráveis existentes no Paraná e particularmente em Curitiba, dentre outras, a proximidade com São Paulo e com o Mercosul, o mercado consumidor local, a infra-estrutura adequada, cabe ressaltar a importância que tem tido no processo de desconcentração um fator por vezes não devidamente destacado, qual seja, a ação do Estado. 


\section{MEIO TÉCNICO-GIENTÍFICO-INFORMACIONAL E \\ AS REGIOEES DO BRASIL - 1999}

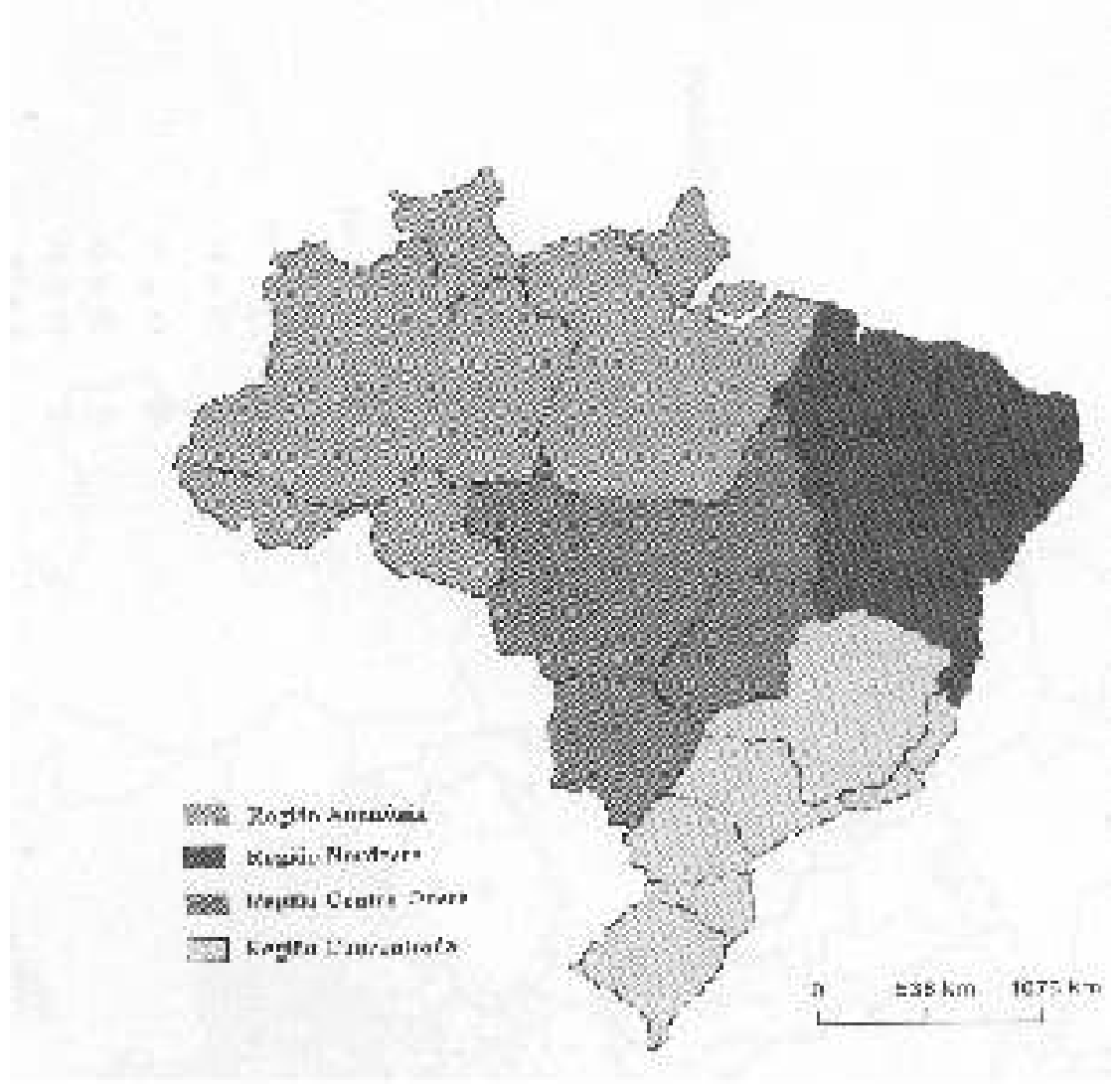

Fonte: SANTOS e SILVEIRA, 2001, p. LXIV

Figura 3: Meio Técnico-Científico-Informacional e as Regiões do Brasil - 1999

Apesar de Diniz (1993) e Diniz e Crocco (1996) considerarem a ação do Estado, é fundamental sublinhar a conotação decisiva que o mesmo passou a ter nos anos de 1990, particularmente por ocasião da corrida desenfreada dos diferentes Estados brasileiros na concessão de incentivos fiscais e financeiros, de modo a atrair para os seus territórios, parcelas dos novos capitais, em sua maioria transnacionais, interessados em localizar suas plantas no Brasil.

Cabe destacar que são as novas unidades implantadas que apresentam uma maior liberdade de localização em relação às localizações mais tradicionais, ou seja, a desconcentração não se faz pela supremacia da transferência de unidades produtivas, mas pela implantação de novos estabelecimentos, muitos dos quais pertencentes a uma mesma empresa e que possuem múltiplas localizações. Tal foi o que ocorreu no 
Paraná, pois a maior parcela dos novos investimentos industriais refere-se a empresas que não atuavam no país, dentre elas Renault e Audi/Volkswagen, e os que já atuavam como fornecedores, instalaram novas unidades específicas para atender a essas demandas, como decorrência dos novos padrões de organização da produção ${ }^{5}$, que requer a localização conjunta da montadora e de seus principais fornecedores ${ }^{6}$.

Parece, portanto, que dentro dessa nova escala espacial de análise, a diferença se fez pelos incentivos oferecidos, uma vez que, medianamente, uma parte das possíveis cidades escolhidas disporia de condições infra-estruturais semelhantes, além de serviços, concentração de pessoas e renda, etc., bem como da proximidade ao grande mercado consumidor do país, além da facilidade de acesso ao Mercosul, que, a despeito das turbulências por que passa a consolidação desse mercado na atualidade, constitui-se num grande atrativo de mercado para as novas indústrias.

\section{Brownfields e greenfields: possibilidades analíticas}

Elegendo-se a perspectiva espacial apontada no início desse texto para as pesquisas em Geografia Industrial, qual seja, aquela que prioriza a relação indústria e espaço geográfico e após as considerações apresentadas sobre as escalas espaciais de análise do processo de desconcentração da indústria, podemos afirmar que tal processo pode se inserir em duas dimensões distintas de análise. A primeira diz respeito a investigação da indústria na escala do urbano, sobretudo do intra-urbano, a segunda se refere a indústria na escala regional aproximando-se, portanto, do inter-urbano.

Na primeira perspectiva, amplia-se, nos últimos anos, uma certa ênfase nos trabalhos que se dedicam a compreender ou a propor mecanismos de intervenção para a superação dos brownfields, que são lugares caracterizados por construções desocupadas, vagas, principalmente plantas industriais? . Nessa perspectiva, a prioridade é a proposição de novos usos através de programas de revitalização para as áreas industriais abandonadas no interior da malha urbana.

Para Vasques e Mendes (2004, s/p), brownfields são "estruturas que testemunham antigas atividades econômicas encerradas. As suas antigas formas, tornam-se obsoletas, incapazes de cumprir novas funções, convertendo-se em enclaves, objetos abandonados em dissonância com o meio onde se inserem".

Assim, no Brasil tais estudos têm se dedicado a compreender a reestruturação do espaço urbano após a aceleração do processo de desconcentração, portanto, o recorte espacial privilegiado tem sido São Paulo. Tal matriz de pensamento apresenta forte influência americana, onde a realidade fez surgir uma série de programas oficiais para revitalização de áreas no âmbito intra-urbano.

$\mathrm{Na}$ segunda perspectiva, aquela onde predomina o enfoque regional, um conceito semelhante na origem, porém oposto no sentido, tem destaque, qual seja o de greenfield.

Para Martin e Veiga (2001, p. 19), tal denominação origina-se também nos Estados Unidos e designa "regiões, em geral interioranas, sem (ou com pouca) tradição na indústria manufatureira, em especial na indústria automobilística". Desse modo, trata-se das greenfields regions, ou seja, regiões cujas características principais são: inexistência de tradição industrial; fraca atuação sindical; baixos salários e governos interessados em atrair investimentos estrangeiros, o que, no Brasil, se manifestou no intenso processo de concessão de incentivos fiscais e financeiros, denominado de "guerra fiscal".

Para os Autores, "os greenfields oferecem excelentes oportunidades para o rebaixamento de custos e aumento das margens líquidas, combinadas sempre com ganhos de escala..." (MARTIN; VEIGA, 2002, p. 21). Parece ser esse o processo predominante no Brasil dos anos de 1990, posto que a acirrada guerra fiscal entre os Estados federados, foi um dos fatores chave para o movimento de desconcentração 
da indústria brasileira.

Portanto, brownfields e greenfields se apresentam como dois lados de um mesmo processo, ou seja, há uma relação direta e oposta entre ambos, tanto na perspectiva da dimensão de análise dos processos: um intra-urbano e outro inter urbano ou regional; quanto no fato de que ambos estão umbilicalmente ligados, na medida em que no processo de busca de greenfields, lugares são transformados em brownfields.

Contudo, a discussão teórica mais aprofundada de tais conceitos está a merecer maior atenção por parte dos geógrafos, bem como trabalhos empíricos, capazes de imprimir maior consistência aos mesmos. Enquanto o conceito de brownfield tem sido muito trabalhado no âmbito dos urbanistas e planejadores, o de greenfield, apresenta uma nítida apropriação pelos sociólogos, sobretudo quando se referem as novas relações sindicais.

O importante parece ser o fato de que ambos os conceitos privilegiam de modo explícito a perspectiva espacial, revelando a intrínseca relação entre espaço e indústria e sua potencial utilização no âmbito da Geografia Industrial.

\section{Considerações Finais}

Pelo exposto, mesmo que brevemente, observa-se que um dos temas mais recorrentes nos trabalhos de Geografia Industrial no Brasil é aquele que trata da desconcentração da indústria e seus impactos tanto nos locais em que a indústria tem deixado de ser a atividade econômica principal (gerando potencialmente brownfields), como nos novos locais onde a indústria se instala e onde não havia nenhuma tradição industrial (regiões greenfields).

Parte de tais trabalhos apóia-se em formulação teórica originária dos anos de 1980, segundo a qual o processo de desconcentração da indústria brasileira ocorreria a partir de São Paulo, alcançando um raio de $150 \mathrm{~km}$ da capital paulista. Tal formulação carece de uma atualização teórico-espacial, sob pena de se aprisionar os processos espaciais contemporâneos em formas pré-definidas e rígidas e que já não correspondem a dinâmica vigente.

Passados mais de vinte anos da proposição dessa aproximação teórica, a mesma ainda é utilizada de modo recorrente por geógrafos, como sendo plena da explicação espacial pretendida, sem que se considere que o tempo foi decisivo na alteração do recorte espacial e que $150 \mathrm{~km}$ a partir de São Paulo na atualidade, não apresenta o mesmo efeito explicativo para a realidade que quando a teoria foi formulada, anos de 1980.

A nova configuração da indústria automobilística, por exemplo, se deu para lugares muito mais distantes que os $150 \mathrm{~km}$, aliás, ocorreu para além dos lugares tradicionais como São Paulo e Minas Gerais. Outra característica importante que deve ser destacada é o fato de que tal explicação limitava-se a compreensão do Estado de São Paulo, certamente porque à época, esse era a expressão máxima do processo de industrialização brasileiro que, contudo, começava a dar sinais de um certo deslocamento das unidades produtivas do aglomerado metropolitano para o interior.

Após os anos de 1990, observa-se uma ampliação do alcance espacial do processo, o que resultou em distintas interpretações, sobretudo por economistas e geógrafos, exemplos são as proposições da aglomeração poligonal e da região concentrada. Assim, seja qual for a opção feita pelo pesquisador, o fato é que a mesma deve considerar uma nova escala de análise demandada para a compreensão dos processos em curso.

Do mesmo modo, tais escalas não devem ter como propósito o aprisionamento de processos 
espaciais, mas permitir uma certa facilitação analítica dos mesmos.

Parece claro que, cada vez mais, a indústria se localiza para além das áreas tradicionais dentro do país ou para as regiões greenfields e as decorrências desse fato, inclusive a formação de brownfields, estão a merecer análises mais profundas pelos geógrafos.

\section{Notas}

(1) Isso se explica pela natureza das investigações que temos efetuado, sobretudo visando compreender a inserção do Estado do Paraná na nova lógica de localização da indústria automobilística nacional (Projeto apoiado pelo CNPq e pela Fundação Araucária do Paraná).

(2) Pacheco (1999, p. 11) chama a atenção para o fato de que a desconcentração e a interiorização da indústria no final dos anos de 1970 e início de 1980 se relaciona ao "acentuado peso para as decisões de política econômica, ou de investimentos a elas associados, tomadas na segunda metade dos anos 70. Muitos desses investimentos, em particular as metas mais ambiciosas do II PND, acabaram sendo revistos e dilatados no tempo, o que favoreceu a continuidade desses processos na primeira metade da década de 80 ".

(3) Note-se que a expressão "desconcentração concentrada" foi utilizada por Azzoni (1985) para se referir ao entorno de São Paulo nos anos 1980, sendo posteriormente utilizada por Pacheco (1999) para se referir à desconcentração restrita ao sudeste e sul do país nos anos 1990. Portanto, visivelmente escalas de análise diferenciadas.

(4) Há que se destacar que a localização da Fiat em Betim na década de 1970, era tomada como exceção a regra geral de localização.

(5) Caracterizadas principalmente pelos sistemas Just In Time e kanban.

(6) Trata-se da materialização da QIV - Quase Integração Vertical, originando complexos de produção flexíveis, condomínios industriais, dentre outras denominações que recebem tais territórios da indústria.

(7) Os brownfields incluem também construções que tiveram outros usos que não exclusivamente o industrial, incluem-se edifícios, estações ferroviárias, galpões de depósito, dentre outros.

\section{Referências}

AZZONI, C. Indústria e reversão de polarização no Brasil: o caso do Estado de São Paulo. São Paulo, 1985, Tese (Livre docência em Economia) - Faculdade de Economia e Administração, Universidade de São Paulo. p. 45-67, 1986.

A lógica da dispersão da indústria no Estado de São Paulo. Estudos Econômicos. São Paulo, n. 16,

DINIZ, C. C. Desenvolvimento poligonal no Brasil: nem desconcentração, nem contínua polarização. Nova Economia. Belo Horizonte, v.3, n. 1, p. 35-64, 1993.

DINIZ, C. C. e CROCCO, M. A. Reestruturação econômica e impacto regional: o novo mapa da indústria brasileira. Nova Economia. Belo Horizonte, v. 6, n. 1, p. 77-103, 1996.

FISCHER, A. Industrie et espace géographique. Paris: MASSON, 1994.

HARVEY, D. A condição pós moderna. Uma pesquisa sobre as origens da mudança cultural. São Paulo: Edições Loyola, 1992. 
LENCIONI, S. Reestruturação urbano-industrial: centralização do capital e desconcentração da metrópole de São Paulo. São Paulo, 1991, 286 f. Tese (Doutorado em Geografia) - Faculdade de Filosofia Letras e Ciências Humanas, Universidade de São Paulo.

MARTIN S. B. e VEIGA J. P. Globalização dos mercados, localização produtiva e relações interfirmas: o caso das montadoras alemãs nos EUA nos anos 1990. In: NABUCO, M. R.; NEVES, M.; CARVALHO NETO, A. (Orgs.). Indústria automotiva: a nova geografia do setor produtivo. Rio de Janeiro: DP\&A, 2002, p. 17-45.

NEGRI, B. Concentração e desconcentração industrial em São Paulo (1880-1990). Campinas: Ed. da UNICAMP, 1996.

PACHECO, C. A. Novos padrões de localização industrial? Tendências recentes dos indicadores da produção e do investimento industrial. Texto para discussão n. 633, Brasília: IPEA, 1999.

RICHARDSON, H. W. City soze and national spatial strategies in developing countries. World Bank Staff Working Paper, n. 252, Washington, 1977.

RODRIGUES, D. A. Os investimentos no Brasil nos anos 90: cenários setorial e regional. Revista do BNDES. Rio de Janeiro, v. 7, n. 13, p. 107-136, 2000.

SAMPAIO, S. S. A industrialização de Rio Claro. Contribuição ao estudo da desconcentração espacial da indústria no Estado de São Paulo. Revista Geografia, Rio Claro, n. 24, p. 01-60, 1987.

SANTOS, M. A urbanização brasileira. São Paulo: Hucitec, 1993.

A natureza do espaço. Técnica e tempo. Razão e emoção. São Paulo: Hucitec, 1996.

SANTOS, M. e SILVEIRA, M. L. O Brasil: território e sociedade no início do século XXI. Rio de Janeiro: Record, 2001.

STORPER, M. Who benefits from industrial descentralization? Social power in the labour market, income distribution and spatial policy in Brasil. Regional Studies, London, v. 18, n. 2, p. 143-164, 1984.

Desenvolvimento econômico e a questão regional: industrialização, polarização e distribuição da renda. inédito, 1987.

TOWNROE, P. e KEEN, D. Polarisation reversal in the State of São Paulo, Brazil. Regional Studies, London, v. 18 , n. 1 , p. 45-54, 1984.

TOWNROE, P e HAMER, A. Who benefits from industrial decentralization? Response to Storper. Regional Studies, London, v. 18, n. 4, p. 339-344, 1984.

VASQUES, A. R. e MENDES, A. A. Redesenvolvimento de brownfields: estudos de casos, desafios e perspectivas. In: Anais do I Seminário Internacional "O desenvolvimento local na integração: estratégias, instituições e políticas. Rio Claro, 2004, disponível em CD. 